\title{
VERSITA
}

Ekológia (Bratislava)

Vol. 32, No. 3, p. 305-319, 2013

doi:10.2478/eko-2013-0027

\section{TRANSFER OF LANDSCAPE ECOLOGICAL KNOWLEDGE FROM THEORY TO PRACTICE AS A MULTISTAGE PROCESS (SELECTED THEORETICAL AND META-SCIENTIFIC ASPECTS)}

\section{FLORIN ŽIGRAI}

Visiting foreign professor (Austria) at Slovak University of Technology in Bratislava, Institute of Management, Department of Spatial Planning, SPECTRA Centre of Excellence EU, Vazovova 5, 81243 Bratislava, Slovak Republic; e-mail: florin.zigrai@a1.net

\begin{abstract}
Žigrai F.: Transfer of landscape ecological knowledge from theory to practice as a multistage process. (Selected theoretical and meta-scientific aspects). Ekológia (Bratislava), Vol. 32, No. 3, p. 305-319, 2013.

Successful and efficient transfer of landscape ecological knowledge from theory to practice is a complex scientific and social topic, the solution of which requires elaboration of suitable theoretical, meta-scientific and empirical-applied research approaches. In this context, the burning question is, to what extent is landscape ecology as a science with its theoretical basis, methodological infrastructure and quantitative-qualitative nature of empirical knowledge prepared to solve this fundamental problem effectively. The transfer of landscape ecological knowledge from theory to practice should be understood as a multistage process bound to bridge and reduce the distances between the theoretical and practical landscape ecological knowledge on the empirical, methodical, theoretical, meta-scientific, didactic and applied level and simultaneously as a great challenge for landscape ecology.
\end{abstract}

Key words: transfer, landscape ecological knowledge, theory, practice.

\section{Introduction}

The issue of the landscape ecological knowledge transfer is given more attention nowadays as confirmed by the following thematically centred symposiums: the 1st IALE-Europe Thematic Symposium on Landscape Ecological Knowledge in Practice with the main topic of 'Implementation of Landscape Ecological Knowledge in Practice' in Poznań (2010) and the 2nd IALE-Europe Thematic Symposium on Landscape Ecological Knowledge in Practice with the main topic 'Implementation of Landscape Ecological Knowledge in European Urban Practice' in Laufen (2011), as well the $16^{\text {th }}$ International Symposium on Problems of Landscape Ecological Research with the main topic of "Landscape Ecology: From Theory to Practice' held in Smolenice (2012). The principal aim of symposium debates was to arrive at a survey of problems and the causes connected with transfer of landscape ecological knowledge from the theoretical to applied sphere. The mentioned problems represent, apart from other, a great challenge for the development of empirics, methodology, theory, didactics and application of landscape ecology (see, e.g. Mizgajski et al., 2010). 
Paradoxically, less attention was given to the study of structure, mechanism and barriers of the mentioned transfer as a multistage process. The problem oriented in this way may, as a matter of fact, greatly contribute to more efficient and accelerated transformation, transfer and implementation of empiric knowledge of the basic landscape ecological research addressing the most important ecological, environmental and socio-economic problems in landscape.

The purpose of this paper is to point out some theoretical meta-scientific aspects of such transfer as a multistage process. In the first part of the contribution, structure and mechanism of landscape-ecological knowledge transfer from theory to practice depending on objects and subjects of landscape ecological research are schematically outlined. In the second part of the article, some measures schemed to obtain more efficient transfer of landscape ecological knowledge from theory to practice are presented.

Some remarks on the structure and mechanism of landscape ecological knowledge transfer from theory to practice depending on objects, approaches and subjects of landscape ecological research

The transfer of landscape ecological knowledge from theory to practice as the multistage process is a complex notion, which consists of the following components that are provided here with short explanation:

Knowledge is defined according to Wikipedia (2013) as 'a familiarity with someone or something, which can include facts, information, description, or skills acquired through experience or education'.

Landscape ecological knowledge is a kind of scientific knowledge, which is generated through empirical, methodical, theoretical, applied, didactic and meta-scientific landscape ecological research approach.

Transfer of landscape ecological knowledge from theory to practice is the time-spatial process of generation, diffusion, transmission, storage and innovation (drivers of transfer process) of obtained knowledge (transferred objects are, e.g., pattern, process and scale) from the theory of basic and applied landscape ecological research to practice of landscape ecology.

Transferred forms of landscape ecological knowledge are, e.g., words, numbers, pictures and transfer media such as press, Internet, TV, radio and personal contacts. The spatial attributes of the landscape ecological knowledge are on the local, regional and national level and temporal attributes are represented by accumulation potentials, continuum and inertia (more in Žigrai, 2001). It was also Szulanski (1999) who drew attention to temporal characteristics of landscape ecological knowledge and their transfer. Szulanski interpreted the knowledge transfer as a temporally reiterating process of the origins and transmission of knowledge. Use of a multistage process for transformation of landscape ecological knowledge has been presented in a teamwork of Vos et al. (2007) involved with preparation of the landscape ecological concept of 'robust corridors' as a part of the Dutch 'National Ecological Network' Project.

According to Turner (2006), the following five factors influence the transfer of landscape ecological knowledge from theory to practice: 'the generation of research capacity, the potential for application, the users of the knowledge, the infrastructure capacity, and the process by which knowledge is transferred'. It seems that the quoted factors reflect the general status and 
development of landscape ecology. It is first of all the reflection of the theoretical, applied and didactic development of landscape ecological research.

This relationship first of all leans on a sustainable balance between theory and practice of landscape ecology (more in Žigrai, 2010a, 2012a). The theory and practice of landscape ecology creates the scientific background for the study of the landscape ecological knowledge transfer.

Theory of landscape ecology is the top generalization and abstraction level of the basic and applied landscape ecological knowledge (e.g. terms, empirical data, research methods and theories). The importance of the theory of landscape ecology for sustainable development and transfer of basic landscape ecological knowledge to practice basically follows from the following:

$\rightarrow$ shaping of quantitative and qualitative characteristic features of landscape-ecological knowledge and its transfer.

$\rightarrow$ acceleration and cheapen of basic and applied research of landscape ecological knowledge transfer.

$\rightarrow$ setting down paradigms, hypotheses, principles and general laws of landscape ecological knowledge transfer .

$\rightarrow \quad$ supporting to establish the learning/science about the transfer of landscape ecological knowledge.

Practice of landscape ecology is the interpretation, evaluation, proposition and implementation of the basic empirical, methodical and theoretical landscape ecological knowledge into landscape ecological planning and management. Importance of the practice of landscape sustainable development and transfer of the basic landscape ecological knowledge to practice follows from:

$\rightarrow$ strengthening the communication and cooperation of the landscape ecologists with socio-political decision-making actors, stakeholders and civic initiatives,

$\rightarrow$ transferring of the landscape ecological thinking and language to those appropriate within the sectors of political, administrative and legislative officials,

$\rightarrow$ deepening of scientific-managerial nature of landscape ecology by means of 'landscape eco-science, 'landscape eco-branding' and 'landscape eco-labelling' and by supporting of the trans-disciplinary character of landscape ecology.

These theoretical-applied properties of landscape ecology form a framework for the efficiency of transfer of landscape ecological knowledge from theory to practice too. This efficiency depends on nature and kind of transfer of landscape ecological knowledge. The effectiveness of the knowledge transfer and its systems depend, according to their salience, credibility and legitimacy and simultaneously depend on communication, translation and mediation between scientific experts and decision-makers. Breuste (2010) pointed out to the causes of a less efficient transition of landscape ecological knowledge into practice from the example on urban landscape research. According to the author, the causes include the scarce interest of landscape ecologists, lack of topical and applicable landscape ecological knowledge and poor interest on side of the political decision-makers to accept them. This is the reason why it is necessary to establish the 'science of landscape ecological knowledge transfer', which may contribute to a more efficient and rapid transition and implementation of the acquired empiric knowledge and skills in the basic landscape ecological research into 
the applied level and help to find solution to ecological, environmental and socio-economic problems of the country. Some remarks to this mission and inherent structure of such scientific discipline will be quoted later in the framework of objects and approaches of landscape ecological research on the meta-scientific level. Structure and mechanism of the landscape ecological knowledge transfer from theory to practice depends on the objects, approaches and subjects of landscape ecological research. A scheme of this relationship follows: (Fig. 1).

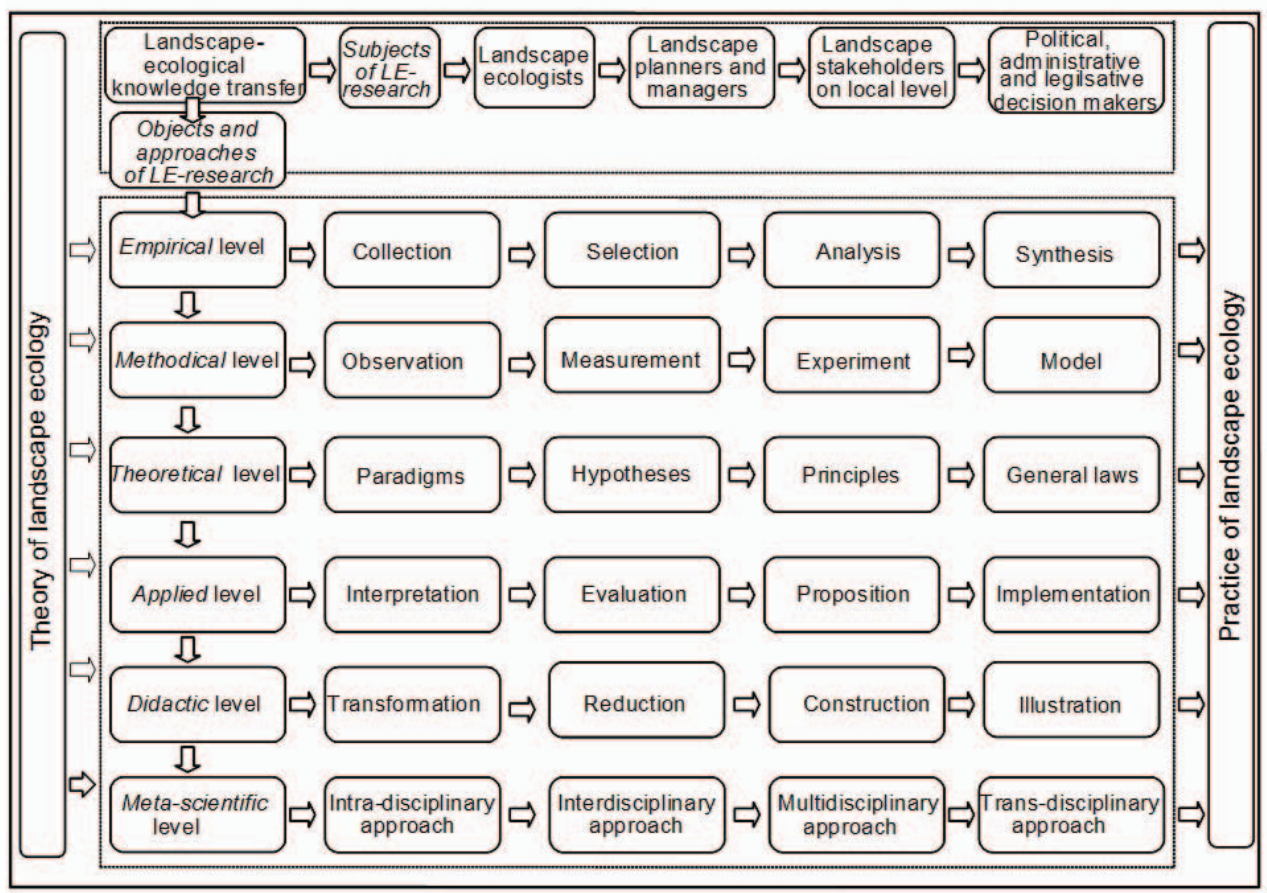

Fig. 1. Scheme of multistage transfer of landscape ecological knowledge from theory into practice.

Objects (what is researched) of landscape ecological research transfers are the knowledge of the relationships between ecological processes and spatial structure (pattern) of complex landscape ecosystems and the human-landscape relationship. The transfer of the relationships takes place on the empirical, methodical, theoretical, applied, didactic and meta-scientific level.

Approaches (how is the object researched) to landscape ecological research are the ways of transferring the landscape ecological knowledge from theory to practice of landscape ecology on the methodical, theoretical, applied, didactic and meta-scientific level.

Subjects (who researches) of landscape ecological research transfer are the participants of this transfer, e.g. landscape ecologists, landscape planners and managers, landscape stakeholders at the local level (inhabitants) as well as political, administrative and legislative decision-makers on various levels. These stakeholders generate the basic landscape ecological 
knowledge, transform it to the applied form and implement it to the landscape plans and then to the political, administrative and legislative decisions.

a) Transfer of landscape ecological knowledge from theory to practice depending on objects and approaches of landscape ecological research.

On the empirical level of landscape ecological research, the transfer of landscape ecological knowledge from theory to practice proceeds in the following operational steps: collection $\rightarrow$ selection $\rightarrow$ analysis $\rightarrow$ synthesis.

$\rightarrow$ Firstly, all problem- and spatial-temporal-oriented data in the framework of basic landscape ecological research should be collected.

$\rightarrow$ Secondly, it is necessary to select pieces from the great amount of data or knowledge that capture and model the character of landscape ecological situation in a given territory.

$\rightarrow$ Selected data or knowledge is then individually analysed and transformed, so that it can be eventually as well as efficiently used in the time-spatial and problem-focused contextual synthesis. In this way it is possible to realize an unproblematic transfer of landscape ecological knowledge from theory to practice.

The transfer mechanism in individual operation steps is probably possible through a kind of membranes that collect, adapt, transform, let through and move into the following operational steps where they are selected, transformed, let through and moved to the third step where they are analysed, transformed, let through and moved to the last operation step where they are transformed into the final synthesized shape. This transfer mechanism of landscape ecological knowledge on example of empiric level is represented by the following scheme: (Fig. 2).

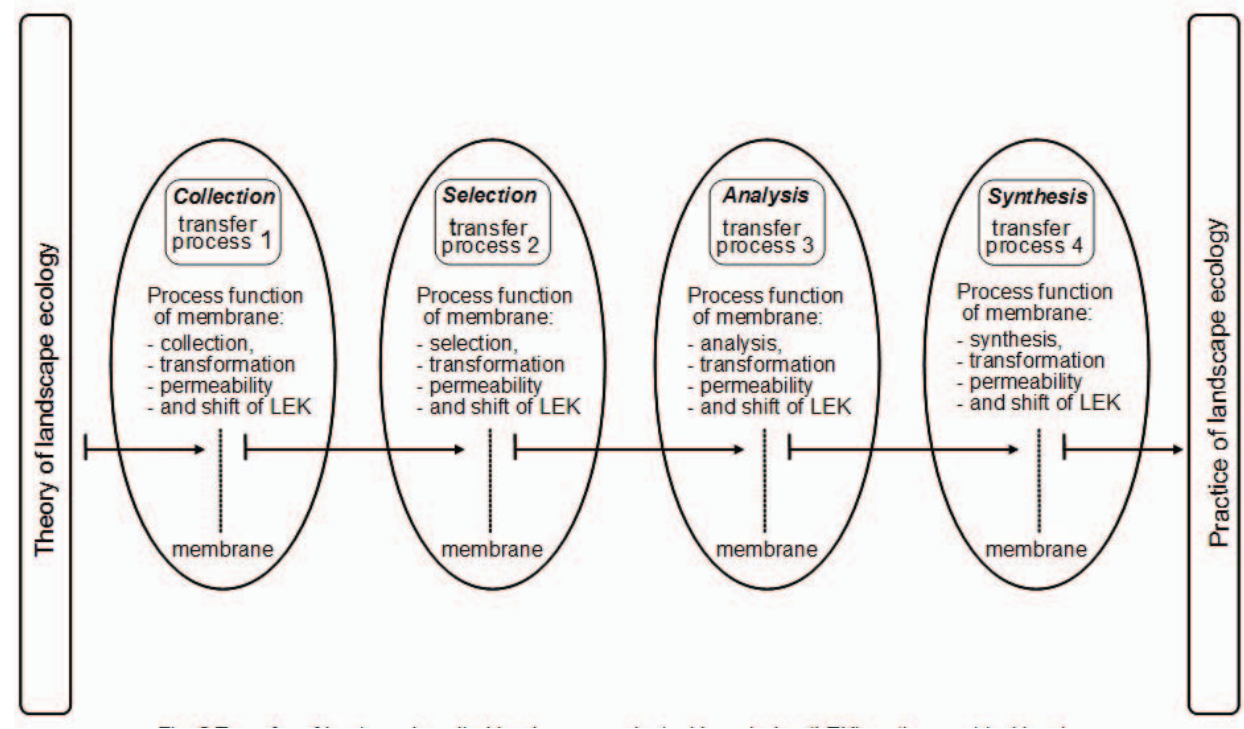

Fig. 2. Transfer of basic and applied landscape-ecologcal knowledg: (LEK) on the empirical level. (Example of mono-discipplinary research approach). 
Transfer of landscape ecological knowledge on the methodological, theoretical, applied, didactic and meta-scientific levels possibly proceeds in a similar way. More attention should be devoted to this issue, which obviously represents one of the important conditions for the efficient transfer of landscape ecological knowledge from theory to applied level, as it has not yet been sufficiently studied.

Transfer of landscape ecological knowledge from theory to practice with its subsequent operation steps: observation $\rightarrow$ measurement $\rightarrow$ experiment $\rightarrow$ model can be accomplished on the methodical level of the landscape ecological research.

$\rightarrow$ The goal of observation is the identification and definition of landscape ecological objects, phenomena, processes.

$\rightarrow$ The goal of measurement is the setting of the quantitative and qualitative value of the observed landscape ecological objects, phenomena and processes.

Field research, i.e. observation, noting down, mapping and qualitative and quantitative measurement, is the tool applicable to the shift of landscape ecological knowledge to a higher methodical stage.

$\rightarrow$ An experiment verifies the way of acquisition and gauging of empiric knowledge. Landscape ecological observation, measurement and experiment are the specific goal-oriented and systematically methodical landscape research forms from the ecological point of view.

$\rightarrow$ The results of landscape ecological observation, measurement and experiment allow to construct the scientific models as simplified and shortened reflections of the complex landscape ecological reality. Such models represent the top conceptual abstraction of landscape ecologists. The unproblematic transfer of landscape ecological knowledge requires their transformation from the real form to an abstract, shortened and generalized one.

On the theoretical level, the transfer of landscape ecological knowledge from theory to practice can be accomplished via the following operation steps: paradigms $\rightarrow$ hypotheses $\rightarrow$ principles $\rightarrow$ general laws.

$\rightarrow$ Generation and transfer of landscape ecological knowledge are also controlled, besides other, by individual stages of the development of universal, scientific, particularly landscape ecological paradigms, which represent the dominant style of thinking and opinion of the scientific community in the concerned science in the particular stage of its development (for more details see Kuhn, 1981; Paulov, 2012; Žigrai, 2002, 2012b). Landscape ecological knowledge obtained by individual landscape ecological paradigms shift them into hypotheses as the following knowledge transfer level.

$\rightarrow$ Meanwhile, landscape ecological hypotheses represent certain scientifically justified but not definitely verified presumptions, which explain some landscape ecological phenomenon or process. Multiple empirical and methodological verifications of a hypothesis push the adapted landscape ecological knowledge to a higher theoretical position, one of the landscape ecological principles.

$\rightarrow$ Landscape ecological principles represent a considerable generalization of landscape ecological knowledge and create a kind of skeleton for landscape ecological research (for more details see Forman, Godron, 1986).

$\rightarrow$ Newly defined landscape ecological principles are crucially important for their transfer to the process generation of universal laws as the top and most difficult and most valuable theoretical level of landscape ecology. Elaboration of landscape ecological laws has to be given more attention in future. 
On the applied level, the transfer of landscape ecological knowledge from theory to practice is accomplished via the subsequent operation steps: interpretation $\rightarrow$ evaluation $\rightarrow$ proposition $\rightarrow$ implementation.

These operation steps have been derived using the example of the landscape ecological planning method LANDEP (Ružička, Miklós, 1982). In this method, the transfer of landscape ecological knowledge or data is supported by an open system, territorial attachment, with high information power, universal application and a narrow interface between the text and cartographic presentation. On the applied level, we can use the collected, selected problem-oriented, analysed and synthesized landscape ecological knowledge worked out on the empirical level. Landscape ecological data adapted in this way are further moved to the following: Interpretation level where they are transformed into a form that facilitates establishment of their ecological suitability for land use in the next evaluation step. The evaluated landscape ecological knowledge serves for optimization of a given territory in terms of ecology in the proposition step. Knowledge in the sphere of landscape optimization is transferred by the implementation step into additional territorial planning documents including the landscape design and management.

On the didactic level, the transfer of landscape ecological knowledge from theory to practice can be made by the subsequent operation steps: transformation $\rightarrow$ reduction $\rightarrow$ construction $\rightarrow$ illustration.

Transformation of landscape ecological knowledge in this case is the one from the scientific to the didactic level to make them compatible in the context of other natural or humanist study subjects.

$\rightarrow$ Reduction of landscape ecological knowledge is simplification and abridgement of the material in order to achieve the concise core, transparency and comprehensibility suitable for pupils and students.

$\rightarrow$ Construction is transformation of the objective landscape ecological knowledge presented by teacher into that which is subjectively perceived by the pupils/students. It should lead to the individual, creative and critical revaluation and organization of the fresh knowledge.

$\rightarrow$ Illustration means transformation of textbook landscape ecological knowledge into pictures or images, which may help pupils/students, emphasize and explain inherent implications of the landscape ecological text.

On the meta-scientific level, the transfer of landscape ecological knowledge from theory to practice is accomplished via the following operation steps: mono-disciplinary or intra-disciplinary $\rightarrow$ interdisciplinary $\rightarrow$ multidisciplinary $\rightarrow$ trans-disciplinary approach.

According to Fry et al. (2007) the relationship between the kind of integrative landscape research, e.g. intra-disciplinary, interdisciplinary, multidisciplinary and trans-disciplinary approach, and the kind of its knowledge is very important.

$\rightarrow$ The intra-disciplinary research approach to the landscape ecological knowledge transfer between theory and practice of landscape ecology by means of their types with their knowledge is presented by the following scheme. (Fig. 3) In this way it is possible to bridge and shorten the distance step by step between the theory and practice of landscape ecology. Simultaneously, the kind of landscape ecological knowledge is transformed from its basic character to the applied one (more in Žigrai, 2010 b). 
A1 = The combination of landscape-ecological types , in sensus stricto " and "ecological " A2 = The combination of landscape-ecological types "theoretical-methodological" and "basic "

B1 = The combination of landscape-ecological types ,in sensus stricto" and "geographical " B2 = The combination of landscape-ecological types "empirical-methodical" and "basic"

$\mathrm{C} 1=$ The combination of landscape-ecological types , in sensus lato" and ,ecological " $\mathrm{C} 2$ = The combination of landscape-ecological types "theoretical-methodological" and "applied"

D1 = The combination of landscape-ecological types "in sensus lato " and "geographical " D2 = The combination of landscape-ecological types „empirical-methodical" and „applied"

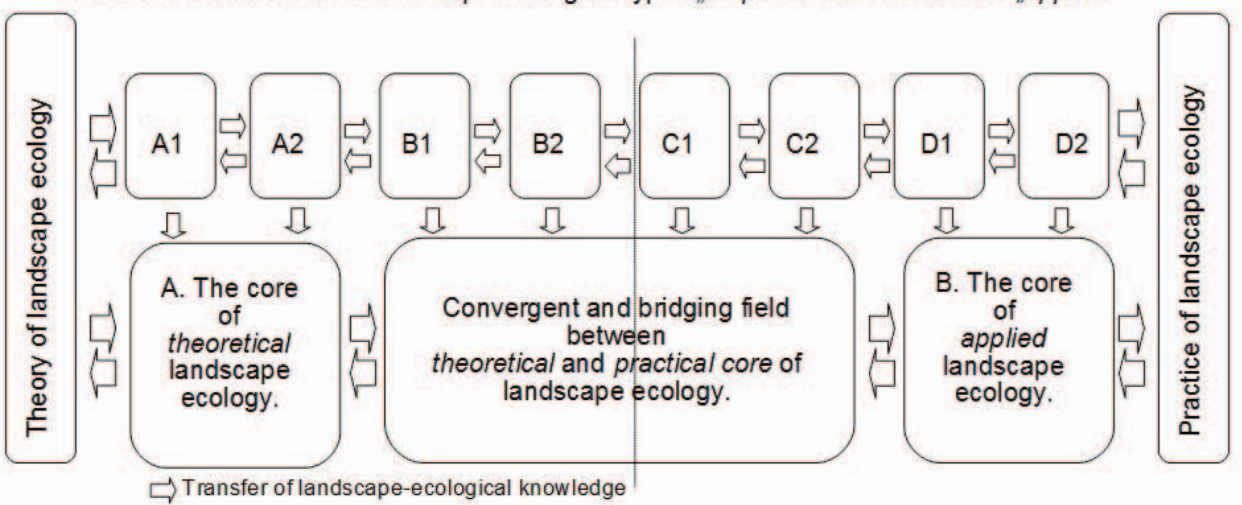

Fig. 3. Scheme of mutual mono- (intra )-disciplinary landscape-ecological knowledge transfer between theory and practice of landscape ecology by means of their types. (Example of intra-disciplin ary research approach).

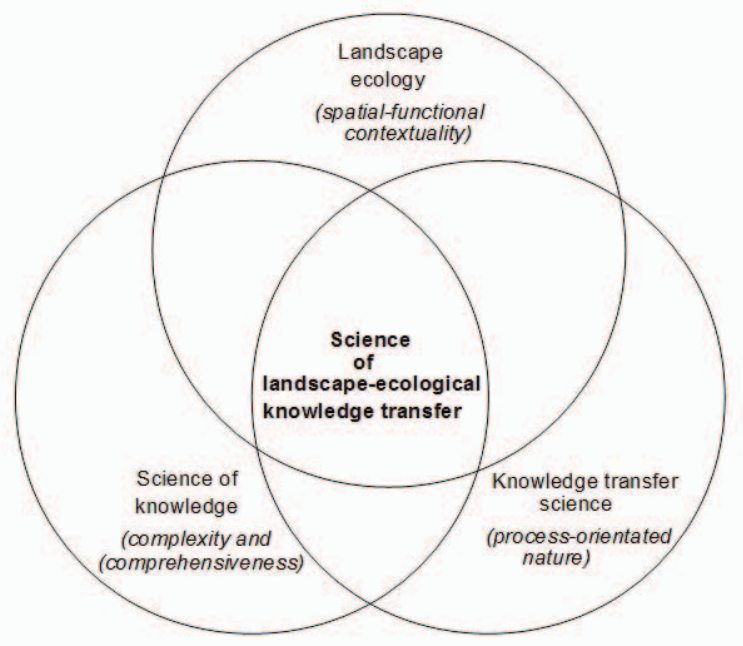

Fig. 4. Scheme of most important sciences supporting the science of landscape-ecological knowledge transfer. (Example of multidisciplinary research approach). 
The interdisciplinary research approach to the landscape ecological knowledge transfer between the theory and practice of landscape ecology on the meta-scientific level is presented via the scheme of the convergence process between landscape ecology and the knowledge transfer science by means of landscape ecological (spatial-functional) and knowledge transfer scientific (process oriented) aspects.

(Fig. 4) The spatial-functional aspect of landscape ecology with its landscape ecological theories and methods helps the knowledge transfer research. On the other hand, the process and complexity orientated aspect of knowledge transfer science helps the landscape ecological research. The spatial-functional and process orientated aspects in the framework of the interpenetration layer of landscape ecology and the knowledge transfer science generate together the landscape ecological and knowledge transfer systems as the main common research topic of landscape ecology and the knowledge transfer science.

$\rightarrow$ The multidisciplinary research approach of the landscape ecological knowledge transfer between theory and practice on the meta-scientific level is presented in the scheme of the most important sciences supporting the science of landscape ecological knowledge (Fig. 5) .

The science of landscape ecological knowledge transfer should represent a very complex scientific field, which lies on the interpenetration area of landscape ecology with its spatialfunctional context, the knowledge transfer science, with its process-orientated nature and science of knowledge with its complexity and comprehensiveness.

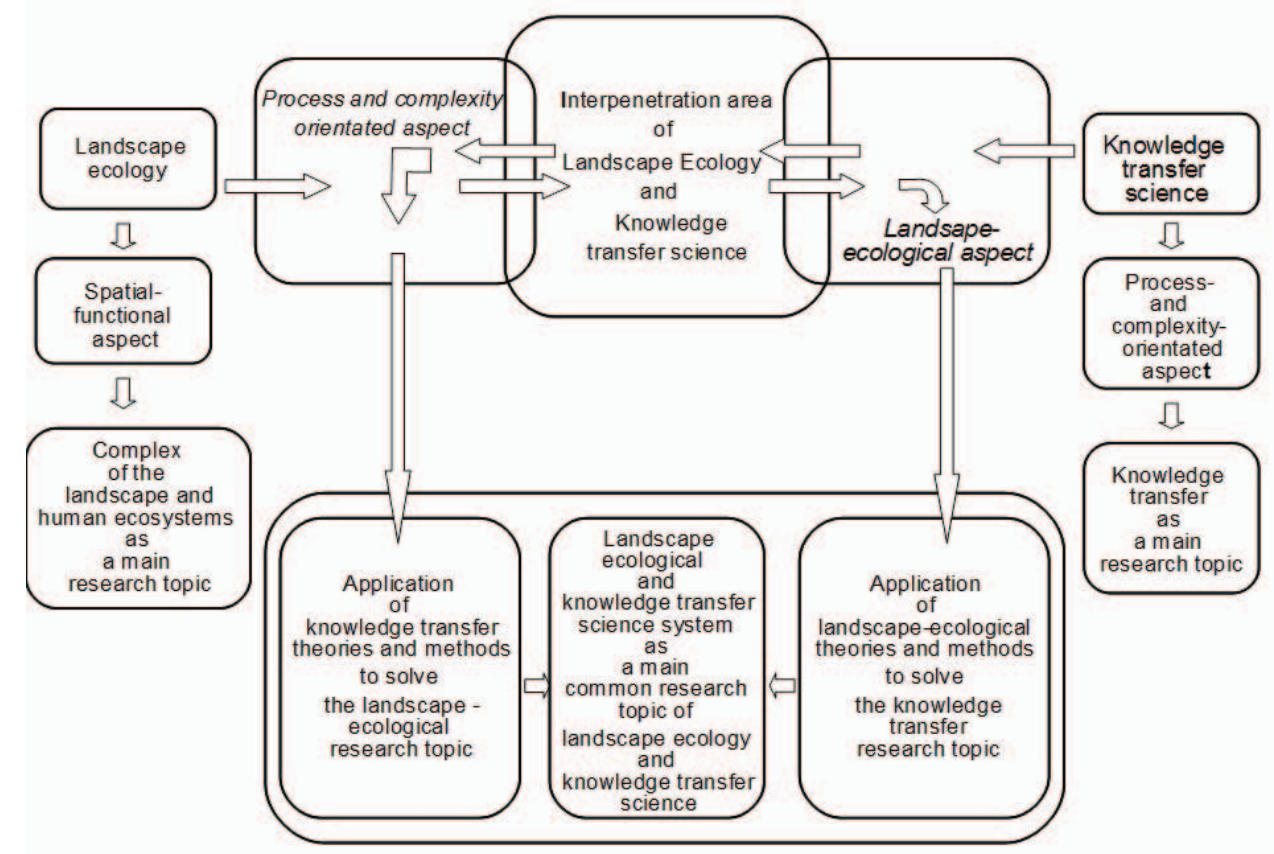

Fig. 5. Scheme of the landscape-ecological and knowledge transfer science system . (Example of interdisciplinary research approach). 
It means that the science of landscape ecological knowledge transfer as a synthesis of partial disciplines may represent a very strong science in terms of information which in turn may contribute to a more efficient transfer of landscape ecological and theoretical knowledge into practice.

$\rightarrow$ The multidisciplinary convergent research approach to the landscape ecological knowledge transfer between theory and practice of landscape ecology on the meta-scientific level is presented by the scheme, which shows convergent fields between the ecological, economic and social sciences and their proper knowledge (Fig. 6).

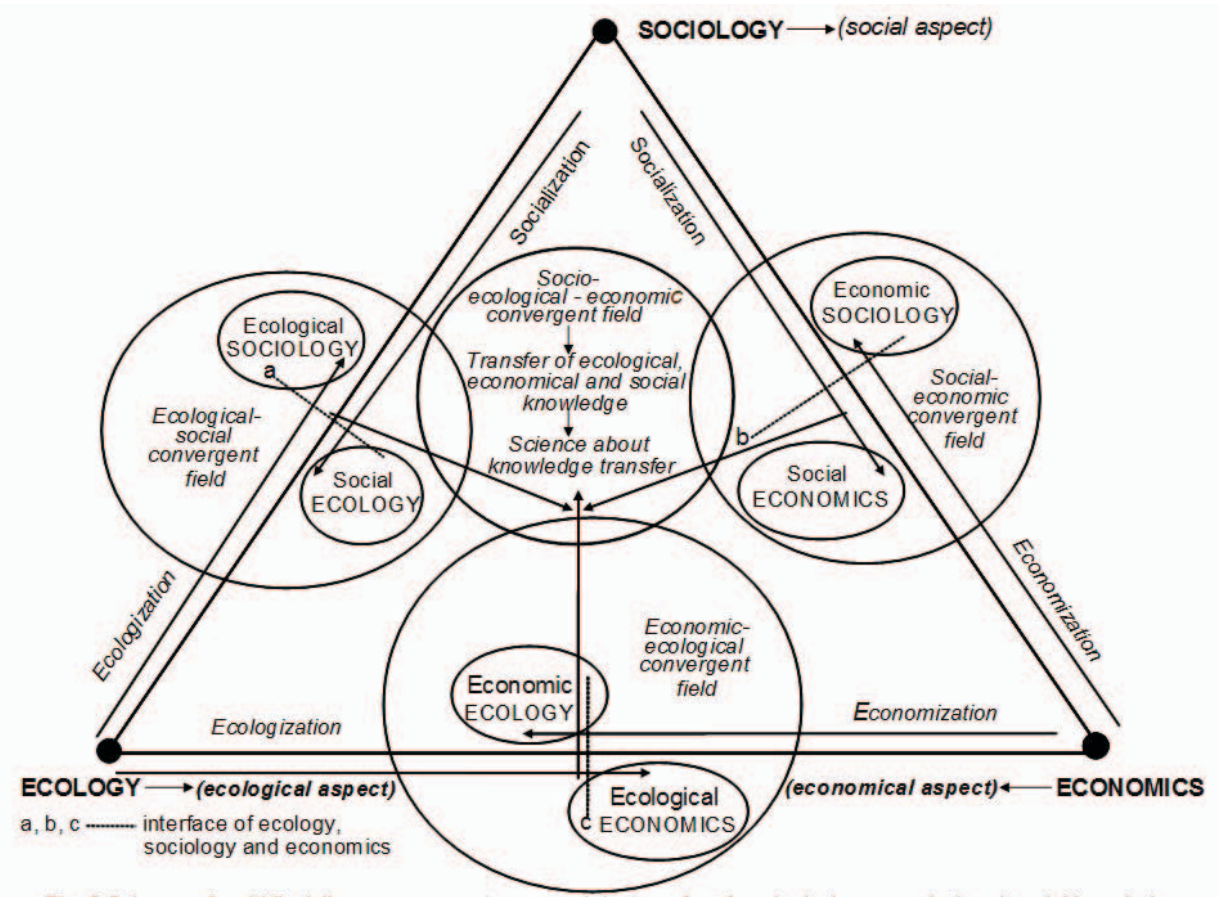

Fig. 6. Scheme of m ultidisciplinary convergent approcah by transfer of ecological, economical and social knowledge.

They are the results of mutual penetration of such processes like ecologization, economization and socialization. Central theme of this multidisciplinary approach is to establish convergent fields of these aspects by means of interpenetration areas of the core scientific disciplines as well as by the bordering disciplines at their mutual cross-points. On both sides of the border lines of the processes, new sub-disciplines, e.g. economic ecology or ecological economics, which form economic-ecological convergent field, emerge. Pursuing the same principle, other sub-disciplines with their convergent fields and

bridging function emerge. These convergent fields provide the bridging function for the transfer of particular ecological, economic and social knowledge. The sense of this multidisciplinary convergent approach is to solve the transfer of landscape ecological knowledge and make it more objective and exact in consideration of the principle of context, complexity, 
integrity, complementarily, mutuality and synergy. Six ecological, economic and social subdisciplines with their convergent fields and proper knowledge, which are the cores of the scientific background to the multistage convergent multidisciplinary approach of ecology, economics and sociology with its knowledge transfer, are presented in following scheme (Fig. 7).

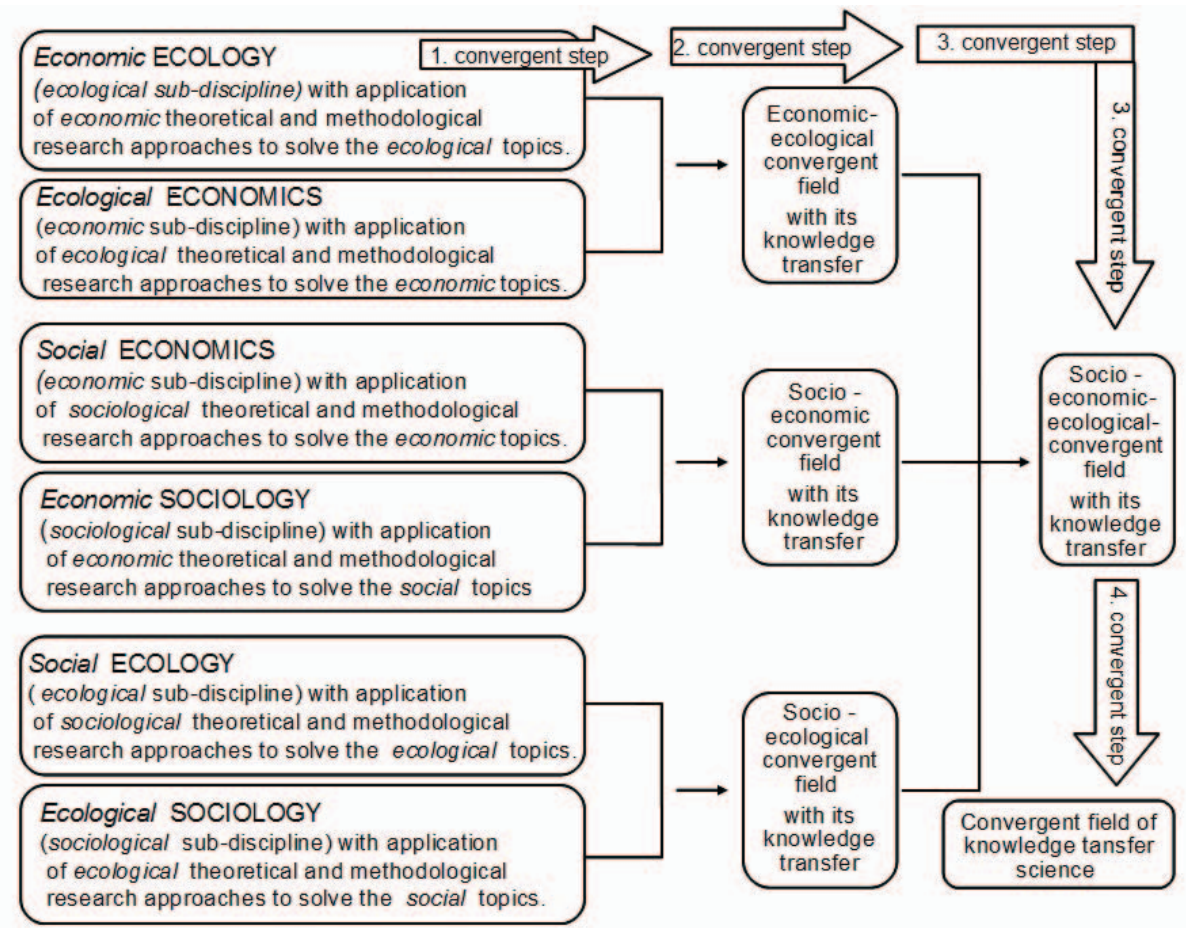

Fig. 7. Scheme of $\mathrm{m}$ ultlstage multidlslcplmary congvergent approach of ecology. econom ICS and sociology with ItS knowledge transfer.

The convergence process of these scientific disciplines with their knowledge basically proceeds in several steps: the first convergent step takes place in each of the six sub-disciplines, e.g. economic convergence in the economic ecology, or ecological convergence in the ecological economics. The second convergent step is the result of the combination of the two closest neighbour sub-disciplines, e.g. economic-ecological convergent field with its knowledge transfer. The third convergent step is the result of the combination of all six sub-disciplines expressed as socio-economic-ecological convergent field with its knowledge transfer. And the fourth convergent step of this knowledge transfer is the convergent field of the knowledge transfer science.

$\rightarrow$ The trans-disciplinary research approach to the landscape ecological knowledge transfer between the theory and practice on the meta-scientific level has the bridging function between objects and approaches on the one hand and the subjects of landscape ecological research on the other. The core of the trans-disciplinary research approach lies in the coop- 
eration between science and practice. In our case it is especially the cooperation between landscape ecology and transfer of its knowledge into the practice, i.e. between landscape ecologists, landscape planners, landscape managers, landscape stakeholders as well as political, administrative and legislative decision-makers at the local and regional level.

b) Transfer of landscape ecological knowledge from theory to practice depending on subjects of landscape ecological research.

The transfer of landscape ecological knowledge from theory to practice depending on subjects can be made via the following operation steps: landscape ecologists $\rightarrow$ landscape planners and managers $\rightarrow$ landscape stakeholders $\rightarrow$ political, administrative and legislative decision-makers on various levels. The cooperation among the landscape ecologists, planners, managers, stakeholders and political decision-makers at the various levels by transfer of landscape ecological knowledge should be very intensive and deep. The results of this cooperation are landscape ecological plans, landscape plans, and landscape design and landscape management with the appropriate knowledge. This new knowledge is very important for the political, administrative and legislative official decision-making at the local and regional level. This intensive cooperation is, according to Nassauer and Opdam (2008), very important for generation of the new landscape knowledge. It is also necessary for the landscape design and landscape change research. Moreover, the transferred ecological knowledge into the landscape planning represents the multistage process as the example of design method for robust corridors (Vos et al., 2007) demonstrates. The scheme of landscape ecological knowledge transfer and cooperation between the landscape ecologists, planners, managers, stakeholders and political decision-makers at the local level is represented by the following scheme (Fig. 8).

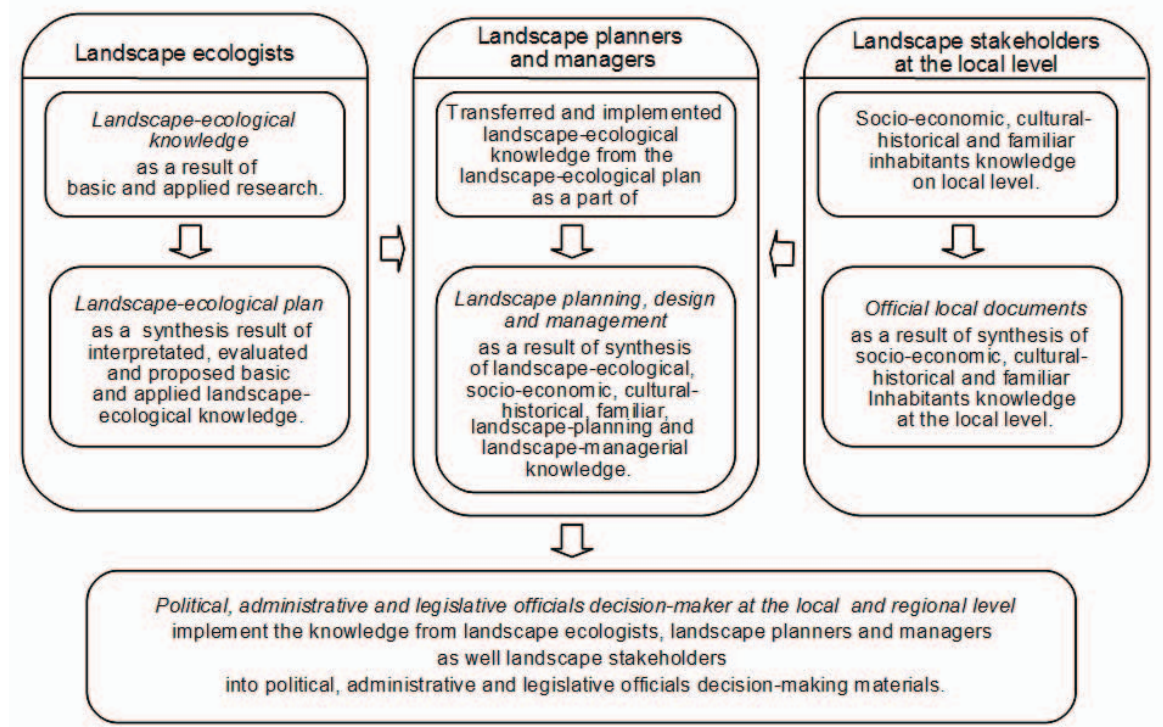

Fig. 8. Transfer of landscape-eoological knowledge and cooperation among the landscape ecologist, planners, managers, stakeholders and political decision-makers. (Example of trans-disciplinary research approach). 
$\rightarrow$ Landscape ecologists should be able to communicate and cooperate with the socio-political decision-making actors and civic initiatives in transformation of basic and applied landscape ecological research for their needs. The key factor is obviously the capability and necessity of transferring the landscape ecological, relational-ecological and spatial-holistic scientific thinking, knowledge and language to those appropriate within the sectors of political, administrative and legislative officials. The landscape ecologists should be able to transform, interpret, evaluate and implement the landscape ecological knowledge of the basic and applied research into the landscape ecological plan, which presents the spatial-functional synthetic results of this knowledge transfer. For this activities landscape ecologists need certain abilities and skills (more in Žigrai, 2013).

$\rightarrow$ The landscape planners and managers should be able to transfer and implement landscape ecological knowledge from the landscape ecological plan to landscape planning, design and management. They are the synthetic results of landscape ecological, socio-economic, cultural-historical, familiar, landscape-planning and landscape-managerial knowledge.

$\rightarrow$ The landscape stakeholders at the local level should be able to transfer and implement the socio-economic, cultural-historical and familiar inhabitant's knowledge on local level into official local documents. They are the synthetic results of this knowledge transfer. Local stakeholders are persons or groups who actively participate and are interested in the landscape planning and landscape managing processes or projects on local or communal levels. They play important but so far not adequately acknowledged roles in an efficient and successful transfer and implementation of landscape ecological level into the official planning documents on local level. It also is one of the reasons why local stakeholders should be permanently engaged in this planning process on local level. Contribution of local stakeholders to the landscape-planning processes, projects and plans is first of all providing the social, cultural/religious and economic knowledge associated with the particular commune or community. This local knowledge discloses the intimacy of the given area and approximates its genius loci, explains its development and transformation in the time-spatial context and stakeholder's place and time attachment. Simultaneously, the local actors point to the imminent natural and social potential of the given locality. The above-quoted knowledge, apart from other, revels the thinking and decision-making processes of local stakeholders who contribute to preparation of landscape plans, territorial management and design on local level. Besides, the knowledge adds the necessary socio-economic dimension to the landscape ecological knowledge both of basic and applied landscape ecological research. Fagerholm and Käayhkoö (2011) pointed out the usefulness of such knowledge representing a kind of 'landscape service'.

$\rightarrow$ The political, administrative and legislative officials and decision-makers at the local and regional level should be able to implement the results of the landscape ecologists, landscape planners and managers as well as landscape stakeholders on the local and regional level into the political, administrative and legislative officials' decision-making materials.

Some remarks on the measures to obtain more efficient transfer of landscape-ecological knowledge from theory to practice

The first approximation of the issue of landscape ecological knowledge transfer from theory to applied sphere as a multi-stage process has been outlined in this paper. It shows that the successful and efficient approach to the problem should be 
$\rightarrow$ to support the intra-, inter- and trans-disciplinary landscape ecological research approaches for higher efficiency of their synergy in the research and solving of the problems connected with the transfer of landscape ecological knowledge from theory to practice;

$\rightarrow$ to prepare the methodical processes of transformation from the theoretical landscape ecological knowledge into the practical one;

$\rightarrow$ to support the multidisciplinary landscape ecological research approach which makes the

transfer of its knowledge from theory to practice more objective and exact in consideration of the principle of context, complexity, integrity, complementarily, mutuality and synergy;

$\rightarrow$ to transform the scientific language of the results of empirical research into the language of practitioners and stakeholders;

$\rightarrow$ to support the convergence of ecological, economic and social sciences for their bridging function by transferring the particular ecological, economic and social knowledge from theory to practice;

$\rightarrow$ to generalize the empirical landscape ecological knowledge into new theoretical regularities and principles, which makes easier its transfer to the practice;

$\rightarrow$ to keep the qualitative and quantitative balance between the theoretical and practical landscape ecological knowledge as one of the most important pre-conditions for the sustainable development of landscape ecology and also for strengthening its social and scientific relevance;

$\rightarrow$ to support the ability and skill of students to prepare, interpret and evaluate the analytical landscape ecological data necessary for the creation of problem-oriented syntheses, as well as to coordinate and cooperate the successful management of teams involved in the landscape ecological planning and design; $\rightarrow$ to work out the foundations of 'science about landscape ecological knowledge transfer' and $\rightarrow$ to deepen the cooperation among the landscape ecologists, planners, managers, stakeholders and political decision-makers at the various levels by the transfer of landscape ecological knowledge from the theory to practice.

\section{Conclusion}

The above-outlined theoretical and meta-scientific remarks on the transfer of the landscape ecological knowledge from theory to practice insinuate that it is a very complex issue requiring the choice of adequate strategies and philosophy for the formulation of measures targeted at increasing the proper measures to obtain more efficient transfer of landscape ecological knowledge from theory to practice. This efficiency depends first of all on the qualitative and quantitative relationship among the objects, approaches and subjects of landscape ecological research. It should be noted that these brief measures constitute part of the meta-landscape-ecological research, and they should proceed permanently complementing each other in parallel, and this will assure their high efficiency facilitating the increase of the landscape ecological knowledge transfer from theory to practice. This transfer should be understood as a multistage process bound to bridge and reduce the distances 
between the theoretical and practical landscape ecological knowledge on the empirical, methodical, theoretical, meta-scientific, didactic and applied level and simultaneously as a great challenge for landscape ecology.

\section{References}

Breuste, J. (2010). Challenges and problems of implementing landscape ecological knowledge in practice - the case of urban development. The Problems of Landscape Ecology, 28, 23-32.

Encyclopedia Wikipedia (2013). (http://en.wikipedia.org./wiki/Knowledge

Fagerholm, N. \& Käayhkoö N. (2011). Can Community Involvement and Participatory Mapping Enhance Assessment of Landscape Service? Case Study from Zanzibar, Tanzania. In The $8^{\text {th }}$ World Congress of the IALE Peking "Landscape ecology for sustainable environment and culture" (pp. 131). Beijing: IALE.

Forman, R.T.T. \& Godron M. (1986). Krajinná ekologie. Praha: Academia.

Fry, G., Tress, B. \& Tress G. (2007). Integrative landscape research: facts and challenges. In J. Wu \& R. Hobbs (Eds.), Key Topics in Landscape Ecology (pp. 246-268). Cambridge: Cambridge University Press.

Kuhn, T.S. (1981). The Structure of Scientific Revolutions (in Slovak). Bratislava: Vydavatel'stvo Pravda.

Mizgajski, A. et al. (2010). Implementation of landscape ecological knowledge - achievements and challenges. The Problems of Landscape Ecology, 28, 9-13.

Nassauer, J.I. \& Opdam P. (2008). Design in science: extending the landscape ecology paradigm. Landsc. Ecol., 23, 633-644. DOI 10.1007/s10980-008-9226-7

Paulov, J. (2012): Basic paradigms in the evolution of geography as a science: an attempt at a brief identification (in Slovak). Geografický Časopis, 64, 2, 111-120.

Ružička, M. \& Miklós L. (1982). Landscape ecological planning (LANDEP) in the process of territorial planning. Ekológia (ČSSR), 1, 3, 297-312.

Szulanski, G. (1999): The process of knowledge transfer: a diachronic analysis of stickiness. Philadelphia: Wharton School, University of Pennsylvania, Department of Management 40.

Turner, M. (2006). Knowledge transfer in Forest Landscape Ecology. In A.H. Perera, L.J. Buse \& T.R. Crow (Eds.), Forest Landscape Ecology: Transferring Knowledge to Practice (pp. 1-2). New York: Springer.

Vos, C., Opdam, P., Steingröver, E. \& Reijnen R. (2007). Transferring ecological knowledge into landscape planning: a design method for robust corridors. In J. Wu \& R. Hobbs (Eds.), Key Topics in Landscape Ecology (pp. 227-245). Cambridge: Cambridge University Press.

Žigrai, F. (2001). Long-term ecological research sites in time-spatial context. (Some theoretical and methodological notes to transformation, allocation and networking of long-term ecological research sites). Ekológia (Bratislava), 20(Suppl. 2), 15-24.

Žigrai, F. (2002). "Paradigm" as a scientifically relevant notion for forecasting the development of landscape ecology (in Slovak). Acta Environmentalica Universitatis Comenianae (Bratislava), 11, 73-85.

Žigrai, F. (2010a). Landscape ecology in theory and practice (selected theoretical and meta-scientific aspects). Ekológia (Bratislava), 29(3), 229-246. DOI: 10.4149/ekol_2010_03_229.

Žigrai, F. (2010b). Typology of landscape ecology (in Slovak). In V. Herber (Ed.), Fyzicko-geografický sborník 8. Fyzická geografie a kulturní krajina (pp. 22-29).Brno: PF Masarykova univerzita.

Žigrai, F. (2012a). Social- scientific relevance of landscape ecology as the reflection of its theoretical-applied and educational development. Ekológia (Bratislava), 31(2), 168-181. DOI: 10.4149/ekol_2012_02_168.

Žigrai, F. (2012b). The paradigm of sustainable development as a preconditions of development of landscape ecology (in Slovak). Ekologické Štúdie, 3(1), 89-101.

Žigrai, F. (2013). Preservation of authenticity and identity of landscape ecology as an assuumption of its further development (in Slovak). In V. Herber (Ed.), Fyzicko-geografickýsborník 11. Fyzická geografie a kulturní krajina v 21. století (pp. 63-71). Brno: PF Masarykova univerzita. 